\title{
Hypomethylation of the Interferon $\gamma$ Gene as a Potential Risk Factor for Essential Hypertension: A Case-Control Study
}

\author{
Xing-Jie Bao, ${ }^{1, *}$ Shu-Qi Mao, ${ }^{2, *}$ Tian-Lun Gu, ${ }^{1}$ Shu-Ying Zheng, ${ }^{1}$ Jin-Shun Zhao ${ }^{1}$ \\ and Li-Na Zhang ${ }^{1}$ \\ ${ }^{1}$ Department of Preventive Medicine, Zhejiang Provincial Key Laboratory of Pathological and Physiological \\ Technology, Medical School of Ningbo University, Ningbo, Zhejiang, China \\ ${ }^{2}$ Beilun District Center for Disease Control and Prevention, Ningbo, Zhejiang, China
}

\begin{abstract}
Essential hypertension (EH) is a multifactorial disease. Interferon- $y$ (IFN- $\gamma$ ) plays an important role in the onset of $\mathrm{EH}$ through cytokine-mediated systemic inflammatory responses. We aimed to determine whether the methylation status of the IFN- $y$ gene (IFNG) promoter is involved in the pathogenesis of EH. Six copies of $\mathrm{CpG}$ dinucleotides are distributed between 3,203 bp and 3,121 bp upstream from the transcription initiation site of IFNG, termed CpG1 to CpG6 in the 5'-to-3' direction. We recruited 96 patients with EH and 96 sex- and age-matched healthy subjects as controls. Using bisulfate pyrosequencing datasets, we analyzed the methylation status of the six $\mathrm{CpG}$ sites and thus found that $\mathrm{CpG} 5$ was consistently methylated in all of the $96 \mathrm{EH}$ patients and 96 control subjects. Among the remaining five $\mathrm{CpG}$ sites, there was no significant difference in the methylation levels of $\mathrm{CpG} 4$ and $\mathrm{CpG} 6$ between the two groups. By contrast, CpG1 $(P=0.003)$ and CpG3 $\left(P=5.87 \times 10^{-7}\right)$ were highly methylated among the EH subjects compared with the controls, whereas CpG2 $\left(P=1.24 \times 10^{-12}\right)$ was significantly less methylated in among EH subjects. The methylation levels of $\mathrm{CpG} 2$ were still lower after adjustment with logistic regression (adjusted $P=$ 0.032). The $\mathrm{CpG} 2$ methylation level was an effective marker of $\mathrm{EH}$ (area under curve $=0.384 ; P=1.40 \times$ $10^{-15}$ ). The present study shows that hypomethylation of the IFNG promoter is significantly related to the risk of $\mathrm{EH}$, providing new insights into the pathogenesis of $\mathrm{EH}$.
\end{abstract}

Keywords: DNA methylation; epigenetic; essential hypertension; Interferon- $\gamma$; promoter

Tohoku J. Exp. Med., 2018 April, 244 (4), 283-290. (C) 2018 Tohoku University Medical Press

\section{Introduction}

Essential hypertension (EH) is a multifactorial disease. A variety of experimental models have elucidated the different mechanisms underlying this disease, and the interactions between behavioral factors (such as high sodium and/or low potassium diet, smoking), environmental factors (long-term mental stress, being overweight, and/ or obese), and genetic factors associated with it (Hamlyn and Manunta 2011; Hering et al. 2013; Wise and Charchar 2016). The World Health Organization stated that the prevalence of increased blood pressured in females aged 18 years and over is approximately $20 \%$, and approximately $24 \%$ in males. In China, the prevalence of $\mathrm{EH}$ is $14.9-$ 29.9\% (http://www.who.int/gho/ncd/risk_factors/blood_ pressure_prevalence/en/).

DNA methylation is an epigenetic modification significantly associated with behavioral and environmental factors; it may affect gene expression (Jjingo et al. 2012).
Aberrant epigenetic modifications often occur on $\mathrm{CpG}$ dinucleotides, which are located in a DNA region rich in guanidine and cytosine in a promoter (Suzuki and Bird 2008). Gene promoter methylation is an epigenetic change leading to either gene silencing or active transcription (Tirado-Magallanes et al. 2017). Additionally, these changes play an important role in the regulation of gene expression, by influencing chromatin structure, DNA conformational stability, and protein-protein interactions without changing the DNA sequence under normal physiological conditions and in the pathogenesis of some diseases (a reversible process) (Feinberg 2008; Rivera et al. 2014). Recent studies have revealed that aberrant DNA methylation is associated with various diseases, such as cancer, cardiovascular disease, rheumatoid arthritis, and periodontal diseases (Ishida et al. 2012; Bergman and Cedar 2013; Glier et al. 2014). Our research group detected aberrant methylation levels in the genes of the renin-angiotensin-aldosterone system [angiotensin II type I receptor (AGTRl) gene and

Received October 24, 2017; revised and accepted March 14, 2018. Published online April 10, 2018; doi: 10.1620/tjem.244.283.

*These authors contributed equally to this work.

Correspondence: Li-Na Zhang, Department of Preventive Medicine, Zhejiang Provincial Key Laboratory of Pathophysiology, Medical School of Ningbo University, 818 Fenghua roads, Ningbo, Zhejiang 315211, China.

e-mail: zhanglina@nbu.edu.cn 
cytochrome P450 11B2 (CYP11B2) gene], epithelial sodium channel (sodium channel gene family), and inflammatory cytokines [Toll-like receptor 2 (TLR2) gene and interleukin $6(I L-6)$ gene], and in EH-related genes [adipocyte determination and differentiation factor 1 gene $(A D D l)$ and glucokinase gene $(G C K)$ ] (Fan et al. 2015a, b; Gu et al. 2016; Mao et al. 2017a, b).

The interferon- $\gamma($ IFN- $\gamma$ ) gene (official symbol: IFNG) is located in the 68154770-68161741 region of human chromosome 12 (https://www.ncbi.nlm.nih.gov/gene/3458), and IFN- $\gamma$ activates antigen-presenting cells and promotes the differentiation of type 1 helper $\mathrm{T}$ cells (Th1 cells) by upregulating the transcription factor T-bet (Zhou et al. 2011). A methylation island is distributed between 3203 and $3121 \mathrm{bp}$ upstream from the transcription initiation site; promoter hypermethylation levels lead to lower gene transcription and vice versa (Deaton and Bird 2011). IFN- $\gamma$ can cause systemic inflammation by promoting cytokine infiltration, expression, and synthesis; it is also protective against intracellular pathogens and cancer (Klinker et al. 2017). IFN- $\gamma$ enhances the class I antigen presentation pathway, induces the replacement of constitutive proteasome subunits in the $\mathrm{CD} 8^{+} \mathrm{T}$ cell population, and independently clears infection and damaged cells of the endothelium as a part of $\mathrm{CD} 8^{+} \mathrm{T}$ cell homeostasis (Denton et al. 2011). Accumulating evidence indicates that IFN- $\gamma$, the first cytokine identified in endothelial cells, induces the expression of major histocompatibility complex genes and enhances the antiviral activity of immune cells (LubinaDąbrowska et al. 2017). Furthermore, some studies revealed that the methylation of proinflammatory-cytokine genes is associated with blood pressure, e.g., genes of C-reactive protein, IL-6, IL-1 beta (IL-1 $\beta$ ), and tumor necrosis factor $\alpha$ (Sullivan et al. 2007; Lópezjaramillo et al. 2008; Bay-Richter et al. 2012; Mao et al. 2017b). However, the methylation status of $I F N G$ among EH patients remains unclear.

In this case-control study, we tested whether methylation of $I F N G$ contributes to the risk of $\mathrm{EH}$, and determined the relation between IFNG methylation levels and clinical indicators in patients with $\mathrm{EH}$.

\section{Materials and Methods}

\section{Sample collection}

The Ethics Committee of the Seventh Hospital of Ningbo City, Zhejiang Province, approved a hospital case-control study of EH, and all participants signed written informed consent forms. A total of 192 individuals, including $96 \mathrm{EH}$ patients and 96 controls, were recruited from the Seventh Hospital for health examination in Ningbo City, Zhejiang, China. The case group was defined as hypertensive based on the following parameters: systolic blood pressure (SBP) $\geq 140$ $\mathrm{mmHg}$ and/or diastolic blood pressure (DBP) $\geq 90 \mathrm{mmHg}$, according to the 2016 guidelines for the diagnosis and management of hypertension in adults (Gabb et al. 2016). In addition, all hypertensive participants were incident cases and did not receive therapy for hypertension, such as drugs or nutritional interventions. The control group, with $\mathrm{SBP}<120 \mathrm{mmHg}$ and $\mathrm{DBP}<80 \mathrm{mmHg}$, had no history of secondary hypertension, diabetes mellitus, myocardial infarction, stroke, renal failure, drug abuse, or other serious diseases, and no family history of hypertension in first-degree relatives; the subjects were matched by age ( \pm 3 years) and by sex with the controls. All the participants were of Han nationality and had resided in Ningbo for at least three generations. A calibrated mercury sphygmomanometer with an adult-size cuff was used to measure blood pressure, according to the standard instructions recommended by the American Heart Association (Perloff et al. 1993). Blood pressure was measured in the supine position at an interval of $\geq 10$ min by two trained healthcare professionals. After 12 hours of overnight fasting, blood samples were drawn from the antecubital vein into vacutainer tubes containing ethylenediamine tetraacetic acid (EDTA), and were stored at $-80^{\circ} \mathrm{C}$ until DNA extraction.

\section{Biochemical analyses}

Biochemical variables, including alanine transaminase (ALT) activity, and concentrations of total cholesterol, triglycerides (TGs), uric acid, high-density lipoprotein (HDL), low-density lipoprotein (LDL), homocysteine (Hcy), urea, glucose, and creatinine as well as the white blood cell (WBC) count, lymphocyte count, monocyte count, and neutrophil granulocyte count were measured on an Olympus AU2700 automatic analyzer (Tokyo, Japan). A nucleic acid extraction analyzer (Lab-Aid 820; Zeesan Biotech, Xiamen City, China) was used to extract genomic DNA from the peripheral-blood samples. The concentration of extracted DNA was measured on an ultramicro nucleic-acid ultraviolet-light tester (NanoDrop 4002; Thermo Fisher Scientific, Waltham, MA, USA).

Genomic DNA was extracted from the stored peripheral-blood samples using a nucleic acid extraction automatic analyzer (Lab-Aid 820). DNA methylation was quantified by sodium bisulfite DNA conversion coupled with pyrosequencing (Jiang et al. 2013). Unmethylated cytosine residues of the target sequences of a candidate gene were first converted to thymine with sodium bisulfite (EpiTech Bisulphite Kit; Qiagen, Hilden, Germany). The converted DNA was selected, and appropriate polymerase chain reaction (PCR) primers were designed in the PyroMark Assay Design software, version 2.0.1.15 (Qiagen). Analysis of $I F N G$ in the University of California Santa Cruz (UCSC) Genome Browser (http://genome.ucsc.edu/) revealed one $\mathrm{CpG}$ island in the region containing the promoter and exon 1 . The PCR products were subsequently denatured with a denaturation solution (Qiagen) and turned into single-stranded DNA for pyrosequencing (Bassil et al. 2013). The PCR mixture consisted of $10 \mu \mathrm{L}$ of ZymoTaq ${ }^{\mathrm{TM}}$ Premix (Zymo Research Corporation, Irvine, $\mathrm{CA}, \mathrm{USA}$ ), $5 \mu \mathrm{L}$ of DNase-and-RNase-free water, $2 \mu \mathrm{L}$ of the converted DNA, and $1.5 \mu \mathrm{L}$ each of the forward and reverse primer. The target was amplified with the forward primer 5'-TGGAGAGTGTTT GTAGTTTT-3' and reverse primer 5'-CTCTATCACCCAAACTAA AATAC-3'; the primer 5'-GAGTGTTTGTAGTTTTAGTTA-3' was employed to detect the target sequence. The reaction program comprised an initial denaturation at $95^{\circ} \mathrm{C}$ for $10 \mathrm{~min}$, followed by 40 cycles at $95^{\circ} \mathrm{C}$ for $30 \mathrm{~s}, 46.7^{\circ} \mathrm{C}$ for $40 \mathrm{~s}$, and $72^{\circ} \mathrm{C}$ for $50 \mathrm{~s}$, and finally, one cycle of $72^{\circ} \mathrm{C}$ for $7 \mathrm{~min}$.

\section{Statistical analysis}

The results are presented as the mean \pm standard deviation (SD) or the number (percentage) of patients. The means of continuous variables such as body-mass index (BMI), neutrophil granulocyte 
count, uric acid levels, total cholesterol levels, and LDL levels between cases and controls were compared by the $t$-test. The Wilcoxon signed-rank test was carried out to analyze non-normally distributed variables such as DNA methylation levels, age, smoking, drinking, HDL, ALT, TGs, urea, creatinine, and WBC. Pearson $\chi^{2}$ or Fisher's exact test was performed to determine the association of $\mathrm{EH}$ and categorical variables including sex, smoking, and drinking. Spearman analysis was conducted to determine the association between IFNG methylation and metabolic characteristics. A receiver operating characteristic (ROC) curve was constructed to analyze the sensitivity of DNA methylation of IFNG for EH diagnosis. Multivariate analysis with logistic regression was performed to analyze the interactions between $I F N G$ methylation and other variables, and to adjust the results for confounding factors. All analyses were conducted in the Predictive Analytics Software (PASW) Statistics 18.0 software (SPSS, Inc., Chicago, IL, USA). 2-sided $P$-values $<0.05$ indicated statistical significance.

\section{Results}

In total, 192 participants aged between 30 and 70 years including 96 patients with EH and 96 sex- and age-matched ( \pm 3 years) controls were enrolled in the present study. Age and sex did not significantly differ between the patients and controls (Table 1). The mean BMI, baseline characteristics, and all metabolic parameters were within the normal ranges. However, there were significant differences in SBP, DBP, HDL levels, TG levels, and uric acid levels between the patients and controls.

We selected a genomic DNA fragment containing six copies of $\mathrm{CpG}$ dinucleotides to explore the association of DNA methylation levels of IFNG (chr12: 6815477068161741) promoter and EH (Fig. 1). These CpG sites are distributed between 3,203 bp and 3,121 bp upstream from the transcription initiation site of $I F N G$, termed CpG1 to CpG6 in the 5'-to-3' direction. Because the fifth CpG dinucleotide site (CpG5) was 100\% methylated in both groups, only the other five $\mathrm{CpG}$ sites were analyzed. The correlation among these five $\mathrm{CpG}$ sites is shown in Fig. 1.

As shown in Table 2 and Fig. 2, methylation levels of $\mathrm{CpG} 1, \mathrm{CpG} 2$, and $\mathrm{CpG} 3$ of the IFNG promoter were significantly associated with EH. CpG1 [patients vs. controls (\%): $37.59 \pm 1.50$ vs. $36.94 \pm 1.60, P=0.003]$ and $\mathrm{CpG} 3$ [patients vs. controls (\%): $21.83 \pm 1.06$ vs. $20.98 \pm 1.07, P$ $=5.87 \times 10^{-7}$ ] were hypermethylated in $\mathrm{EH}$, when compared to the controls, whereas $\mathrm{CpG} 2$ was hypomethylated [patients vs. controls (\%): $9.23 \pm 0.83$ vs. $10.50 \pm 0.92, P=$ $\left.1.24 \times 10^{-12}\right]$. After the logistic regression analysis, the final model included the DNA methylation level of $I F N G$ $\mathrm{CpG} 2$ in the equation (adjusted $P=0.032$ ). In contrast,

Table 1. Comparison of characteristics between controls and EH groups.

\begin{tabular}{lcccc}
\hline Characteristics & $\begin{array}{c}\text { Controls } \\
(\text { Mean } \pm \mathrm{SD})\end{array}$ & $\begin{array}{c}\text { EH } \\
(\text { Mean } \pm \mathrm{SD})\end{array}$ & $t(\mathrm{Z}) / \chi 2$ & $P$ \\
\hline Age & $56.3 \pm 8.2$ & $56.7 \pm 8.7$ & 0.32 & 0.747 \\
Sex $(\mathrm{M} / \mathrm{F})$ & $38 / 58$ & $38 / 58$ & $/$ & $/$ \\
Smoking $(\mathrm{Y} / \mathrm{N})$ & $79 / 17$ & $69 / 27$ & 2.95 & 0.086 \\
Drinking $(\mathrm{Y} / \mathrm{N})$ & $65 / 31$ & $56 / 40$ & 1.81 & 0.178 \\
BMI $\left(\mathrm{kg} / \mathrm{m}^{2}\right)$ & $22.16 \pm 2.30$ & $23.6 \pm 3.09$ & 4.09 & $9.1 \times 10^{-5}$ \\
SBP $(\mathrm{mmHg})$ & $115.05 \pm 8.16$ & $145.10 \pm 9.73$ & 23.19 & $2.67 \times 10^{-57}$ \\
DBP $(\mathrm{mmHg})$ & $71.73 \pm 5.35$ & $90.28 \pm 6.65$ & 21.30 & $3.17 \times 10^{-52}$ \\
HDL $(\mathrm{mmol} / \mathrm{L})$ & $7.99 \pm 6.32$ & $2.07 \pm 5.58$ & 6.57 & $2.6 \times 10^{-9}$ \\
LDL $(\mathrm{mmol} / \mathrm{L})$ & $3.21 \pm 0.87$ & $3.31 \pm 0.68$ & 0.90 & 0.370 \\
ALT $(\mathrm{IU} / \mathrm{L})$ & $26.41 \pm 16.1$ & $28.27 \pm 12$ & 0.89 & 0.370 \\
TGs $(\mathrm{mmol} / \mathrm{L})$ & $1.21 \pm 0.68$ & $1.43 \pm 0.72$ & 2.33 & 0.022 \\
Total cholesterol & $5.19 \pm 0.89$ & $5.38 \pm 0.61$ & 1.71 & 0.091 \\
$(\mathrm{mmol} / \mathrm{L})$ & $4.96 \pm 1.07$ & $5.03 \pm 1.11$ & 0.52 & 0.607 \\
Urea $(\mathrm{mmol} / \mathrm{L})$ & & & & \\
Uric acid $(\mu \mathrm{mol} / \mathrm{L})$ & $300.32 \pm 73.15$ & $325.75 \pm 82.63$ & 2.75 & 0.007 \\
Creatinine & $82.68 \pm 12.28$ & $83.46 \pm 11.04$ & 0.53 & 0.600 \\
$(\mu \mathrm{mol} / \mathrm{L})$ & $5.59 \pm 0.93$ & $6.17 \pm 0.98$ & 4.84 & $1.30 \times 10^{-6}$ \\
WBC count & $1.98 \pm 0.61$ & $2.1 \pm 0.55$ & 2.05 & 0.040 \\
Lymphocyte count & $0.30 \pm 0.18$ & $0.31 \pm 0.17$ & 0.49 & 0.622 \\
Monocytes count & & & & \\
Neutrophile & $3.05 \pm 0.97$ & $3.35 \pm 0.92$ & 2.55 & 0.011 \\
granulocyte count & & & & \\
\hline
\end{tabular}

$P$ value less than or equal to 0.05 is in italics.

BMI, body mass index; SBP, systolic blood pressure; DBP, diastolic blood pressure; HDL, high-density lipoprotein; LDL, low-density lipoprotein; ALT, alanine transaminase; TGs, triglycerides; WBC, white blood cell. 


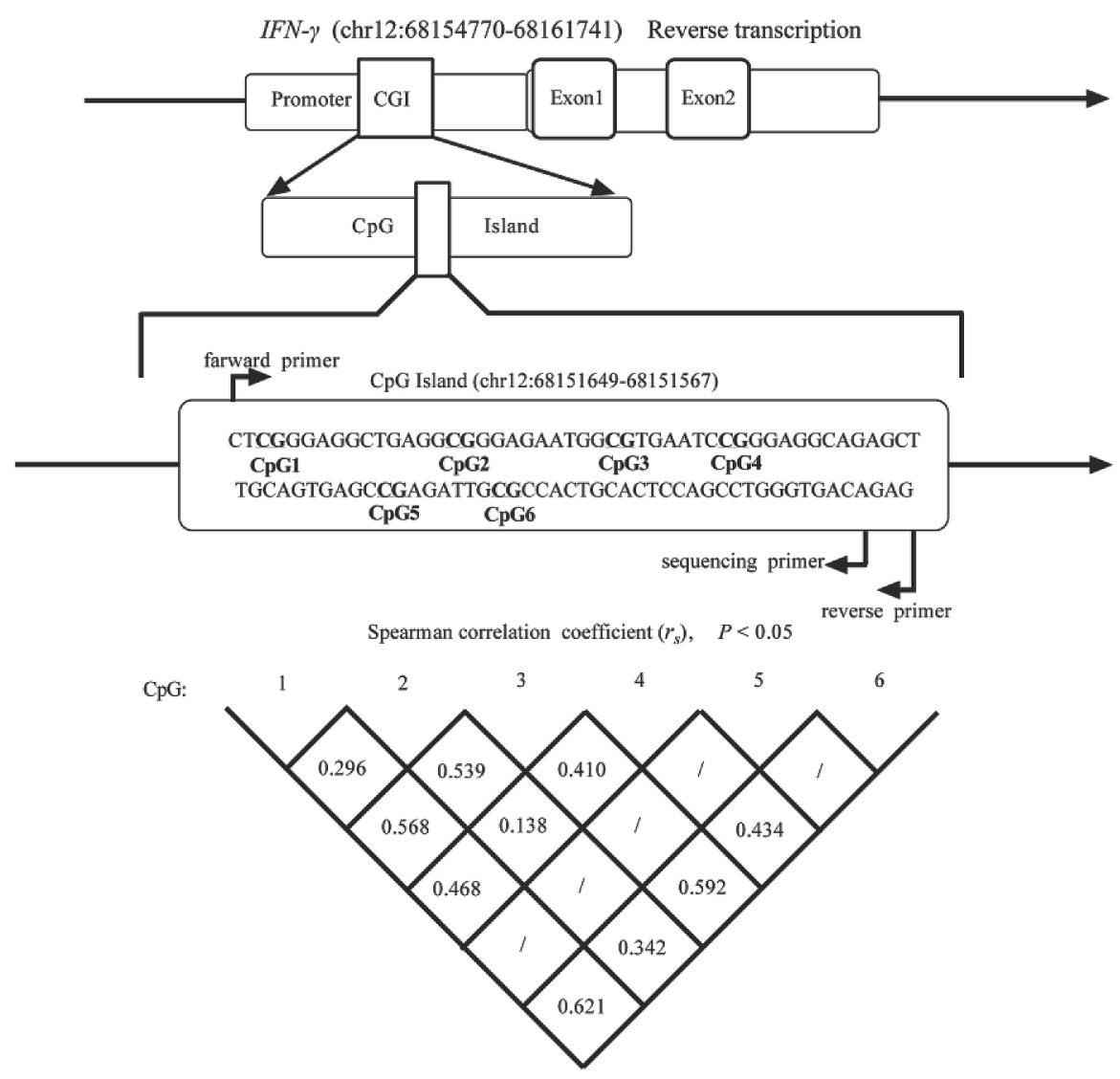

Fig. 1. Six $\mathrm{CpG}$ sites located in the $I F N G$ promoter region. Genomic positions and functional annotations of $I F N G$ were retrieved from the UCSC Genome Browser according to the human genome version 2013 (GRCh38/hg18).

Table 2. Logistic regression analysis of the six CpG sites methylation levels.

\begin{tabular}{|c|c|c|c|c|c|c|}
\hline \multirow{2}{*}{ Variables } & \multirow{2}{*}{$\begin{array}{c}\text { Controls } \\
(\text { Mean } \pm \text { SD) }\end{array}$} & \multirow{2}{*}{$\begin{array}{c}\text { EH } \\
(\text { Mean } \pm \text { SD })\end{array}$} & \multirow{2}{*}{$Z$} & \multirow{2}{*}{$P$} & \multicolumn{2}{|c|}{ Controls vs EH } \\
\hline & & & & & OR $(95 \% \mathrm{CI})$ & $P^{*}$ \\
\hline CpG1 & $36.94 \pm 1.60$ & $37.59 \pm 1.50$ & 2.94 & 0.003 & $1.874(0.26-13.65)$ & 0.535 \\
\hline $\mathrm{CpG} 2$ & $10.50 \pm 0.92$ & $9.23 \pm 0.83$ & 7.10 & $1.24 \times 10^{-12}$ & $0.005\left(4.4 \times 10^{-5}-0.64\right)$ & 0.032 \\
\hline CpG3 & $20.98 \pm 1.07$ & $21.83 \pm 1.06$ & 5.00 & $5.87 \times 10^{-7}$ & $10.835(0.15-773.22)$ & 0.274 \\
\hline CpG4 & $27.04 \pm 3.16$ & $26.97 \pm 2.34$ & 0.363 & 0.717 & $0.912(0.30-2.77)$ & 0.871 \\
\hline CpG5 & 100 & 100 & 1.00 & 1.00 & l & l \\
\hline CpG6 & $31.66 \pm 1.30$ & $31.93 \pm 1.51$ & 1.40 & 0.162 & $0.062(0.001-2.71)$ & 0.149 \\
\hline
\end{tabular}

*Adjust for age, sex, smoking, drinking, uric acid, HDL and BMI.

there was no significant association between the remaining four $\mathrm{CpG}$ methylation levels after adjustment for age, sex, smoking, drinking, uric acid levels, creatinine levels, TG levels, HDL levels, and BMI (Fig. 2, Table 2).

Moreover, significantly higher CpG1 [males vs. females (\%): $37.58 \pm 1.31$ vs. $36.52 \pm 1.64, P=2.6 \times 10^{-4}$ ], CpG4 [males vs. females (\%): $28.16 \pm 2.62$ vs. $26.31 \pm$ $3.29, P=0.007$ ], and CpG6 [male vs. female (\%): $32.0 \pm$ 1.01 vs. $31.43 \pm 1.43, P=0.006]$ DNA methylation levels were observed in males than in females within the control group, but only the difference in CpG1 methylation levels (adjusted $P=0.024$ ) was statistically significant after adjustment for age, smoking, drinking, uric acid levels, HDL levels, TG levels, and BMI. (Table 3).

In addition, the $\mathrm{CpG} 2$ methylation level was found to be an effective marker of EH [Fig. 3; area under curve $(\mathrm{AUC})=0.834 ; P=1.40 \times 10^{-15} \mathrm{]}$. By contrast, methylation at the remaining four $\mathrm{CpG}$ sites was not a successful diagnostic marker of EH.

We also performed correlation tests between IFNG 


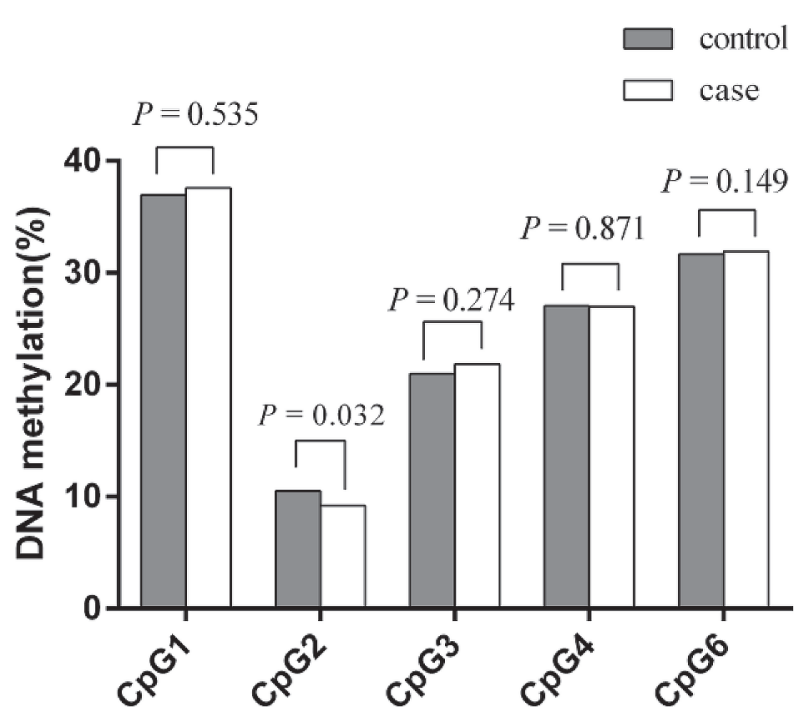

Fig. 2. Significant difference in methylation levels of $\mathrm{CpG} 2$ between the control and $\mathrm{EH}$ groups.

"Case" indicates subjects with essential hypertension $(\mathrm{EH})$, and "control" indicates subjects without $\mathrm{EH}$.

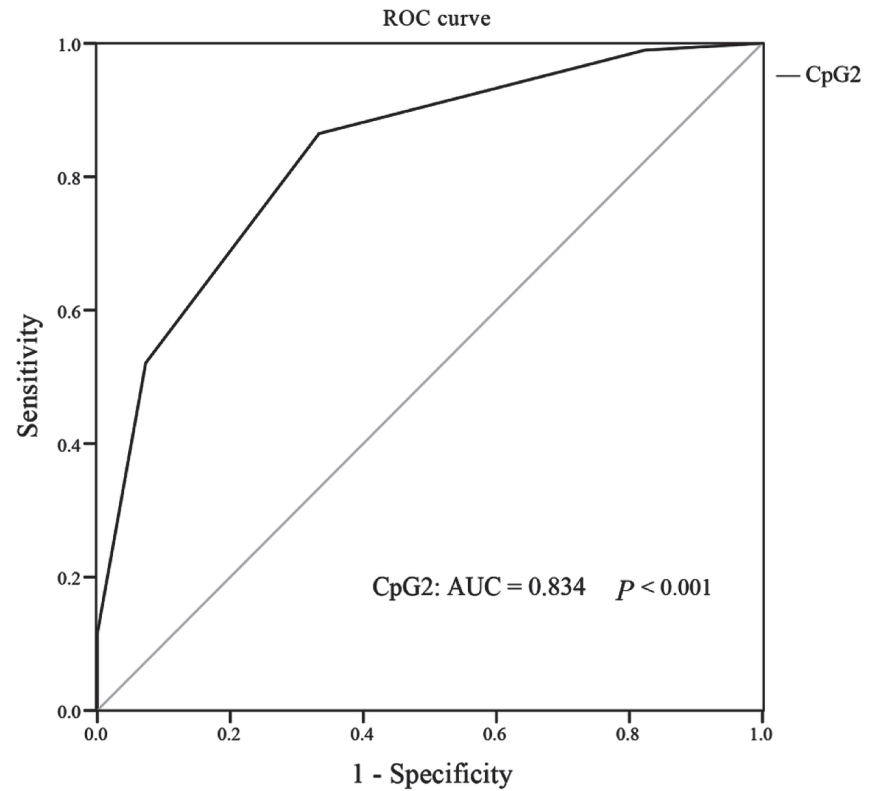

Fig. 3. A receiver operating characteristic (ROC) curve showing the $\mathrm{CpG} 2$ methylation of IFNG in EH group.

Table 3. Logistic regression analysis of the six $\mathrm{CpG}$ sites methylation levels between male and female in control group.

\begin{tabular}{ccccccc}
\hline \multirow{2}{*}{ Variables } & \multirow{2}{*}{$\begin{array}{c}\text { Male } \\
(\mathrm{n}=38)\end{array}$} & $\begin{array}{c}\text { Female } \\
(\mathrm{n}=58)\end{array}$ & $\mathrm{Z}$ & $P$ & \multicolumn{2}{c}{ Male vs. Female } \\
\cline { 6 - 7 } & & & & OR $(95 \% \mathrm{CI})$ & $P^{*}$ \\
\hline CpG1 & $37.58 \pm 1.31$ & $36.52 \pm 1.64$ & -3.65 & $2.6 \times 10^{-4}$ & $0.38(0.16-0.88)$ & 0.024 \\
$\mathrm{CpG} 2$ & $10.53 \pm 1.08$ & $10.48 \pm 0.80$ & -0.39 & 0.70 & $0.54(0.17-1.78)$ & 0.312 \\
$\mathrm{CpG} 3$ & $20.87 \pm 1.10$ & $21.05 \pm 1.05$ & -0.87 & 0.38 & $4.33(0.95-19.91)$ & 0.059 \\
CpG4 & $28.16 \pm 2.62$ & $26.31 \pm 3.29$ & -2.719 & 0.007 & $0.70(0.48-1.02)$ & 0.064 \\
CpG5 & 100 & 100 & 0 & 1.00 & $/$ & $/$ \\
CpG6 & $32.0 \pm 1.01$ & $31.43 \pm 1.43$ & -2.75 & 0.006 & $0.91(0.34-2.50)$ & 0.853 \\
\hline
\end{tabular}

*Adjust for age, smoking, drinking, uric acid, HDL, BMI and TGs.

DNA methylation levels and metabolic phenotypes in the controls (Table 4). Significant correlations were observed between $\mathrm{CpG} 2$ methylation and creatinine levels $\left(r_{s}=\right.$ $-0.207 ; P=0.043)$, glucose levels $\left(r_{s}=-0.218 ; P=0.033\right)$, and smoking $\left(r_{s}=-0.226 ; P=0.050\right)$. By contrast, no significant differences were detected in SBP, DBP, HDL levels, TG levels, and uric acid levels.

\section{Discussion}

Some studies showed that IFN- $\gamma$ can exert immune regulation, anticancer, and antimicrobial activities, affect vascular endothelial cells, and regulate blood pressure by binding to vascular smooth muscle cells in vitro (Gozalbo et al. 2014; Zhou et al. 2014; Lin et al. 2017). In this study, we hypothesized that aberrant $I F N G$ methylation plays a major role in the development of EH. Results revealed hypomethylation of $I F N G$ in the samples from the $\mathrm{EH}$ patients, when compared to those from the controls. These results also uncovered that methylation status of the $I F N G$
CpG2 site was significantly correlated with $\mathrm{EH}$; the analysis of risk factors may provide insights into the pathogenesis of EH.

Generally, promoter hypomethylation promotes transcription, whereas hypermethylation inhibits it (Castro et al. 2003; Deaton and Bird 2011). One research group found that DNA is hypomethylated in peripheral-blood leukocytes in patients with atherosclerotic cardiovascular disease (Aavik et al. 2015). In vascular tissues, lower levels of DNA methylation increase the susceptibility to mutations or abnormal gene expression patterns by increasing the deposition of vascular smooth cells and lipids, resulting in changes from the normal phenotype to vascular fibrotic lesions (Kawano et al. 2014). The results of the present study suggest that epigenetic modification of the $I F N G$ promoter regulates the expression of IFN- $\gamma$ and contributes to a continuous elevation of blood pressure. According to a previous report, aberrant methylation of IFNG directs chemotaxis into the vascular endothelium in $\mathrm{EH}$ patients with 
Table 4. Spearman's rank correlation analyses between the CpG2 site methylation levels and characteristics in control group.

\begin{tabular}{|c|c|c|}
\hline \multirow{2}{*}{ Characteristics } & \multicolumn{2}{|c|}{$\mathrm{CpG} 2$} \\
\hline & $r_{s}$ & $P$ \\
\hline BMI $\left(\mathrm{kg} / \mathrm{m}^{2}\right)$ & -0.102 & 0.324 \\
\hline Sex & -0.040 & 0.699 \\
\hline Age & -0.132 & 0.200 \\
\hline Urea (mmol/L) & -0.141 & 0.172 \\
\hline Creatinine $(\mu \mathrm{mol} / \mathrm{L})$ & -0.207 & 0.043 \\
\hline Uric acid $(\mu \mathrm{mol} / \mathrm{L})$ & -0.113 & 0.273 \\
\hline TGs (mmol/L) & -0.103 & 0.318 \\
\hline $\begin{array}{l}\text { Total cholesterol } \\
(\mathrm{mmol} / \mathrm{L})\end{array}$ & 0.120 & 0.246 \\
\hline HDL (mmol/L) & -0.086 & 0.407 \\
\hline LDL (mmol/L) & 0.079 & 0.442 \\
\hline Glucose (mmol/L) & -0.218 & 0.033 \\
\hline ALT (IU/L) & -0.008 & 0.935 \\
\hline $\mathrm{SBP}(\mathrm{mmHg})$ & -0.160 & 0.120 \\
\hline DBP (mmHg) & -0.097 & 0.346 \\
\hline Smoking & -0.226 & $0.050^{*}$ \\
\hline Drinking & -0.134 & $0.600 *$ \\
\hline
\end{tabular}

*Spearman's rank correlation analyses between the $\mathrm{CpG} 2$ site methylation levels and characteristics in male group.

long-term exposure to low levels of injury and infiltration of Th1 cells (Dong et al. 2013), whereas another study revealed that cardiovascular risk factors serve as evidence of a chronic low-grade inflammatory state in humans and other animals (Taddei et al. 2006) . One study showed that IFN- $\gamma$ can affect vascular endothelial cells and regulate blood pressure by binding to vascular smooth muscle cells in vitro (Zhou et al. 2014).

Some studies indicate differences in DNA methylation levels due to sex among EH patients (Zacharia et al. 2003; Ulrich et al. 2012). Thus, EH is affected by a variety of factors, including DNA methylation levels and sex (Mitu et al. 2013). As previously reported (Post et al. 1999; Bynoté et al. 2008; Choubey et al. 2011), the levels of IFNG methylation correlate with sex hormone levels; this finding is consistent in part with the results of the present study. CpG1, CpG4, and CpG6 showed significant differences between males and females (see Table 3). Additional studies are needed to clarify the relationship between sex hormones and the aberrant methylation of IFNG.

Smoking is a risk factor for EH. Some researchers confirmed and expanded the list of DNA methylation markers associated with smoking, and methylation levels show a linear relation with current and past exposure to smoking (Zhang et al. 2016). In our study, $\mathrm{CpG} 2$ was also negatively correlated with smoking. Biomarkers of smoking exposure (such as cotinine), the number of cigarettes smoked per day, and dose-response relations have been evaluated elsewhere to assess the levels of DNA methylation corresponding to current and past smoking exposure (Zhang et al. 2014; Reynolds et al. 2015). After smoking cessation, $751 \mathrm{CpG}$ sites were found to be significantly correlated with smoking status; besides, dynamic changes in methylation and 1501 CpG sites of DNA in buccal cells have been associated with smoking (Guida et al. 2015; Teschendorff et al. 2015). On the basis of these studies, we can conclude that DNA methylation and smoking can affect the risk of EH.

A positive correlation between plasma glucose levels and blood pressure has been reported (Yan et al. 2016). Additionally, there is a strong correlation between glycolytic activity and IFN- $\gamma$ production (Jacobs et al. 2008; Carr et al. 2010; Macintyre et al. 2014). In the present study, a significant relationship was found between plasma glucose levels and $\mathrm{CpG} 2$ methylation status. One research group showed that glucose is particularly important for initiating IFNG translation, and that it induces the degradation of glyceraldehyde-3-phosphate dehydrogenase, which binds to the 3'-untranslated region of IFNG mRNA, and thus regulates IFN- $\gamma$ expression (Chang et al. 2013). These results indicate that $I F N G$ gene methylation plays a role in $\mathrm{EH}$ risk through the above pathways.

Creatinine is also significantly and independently associated with cardiovascular disease (Wang et al. 2001). In immune-system diseases, the levels of creatinine have been found to increase with IFN- $\gamma$ levels (Amirzargar et al. 2005; Mohammadnia et al. 2011; Yazici et al. 2014). In the present study, creatinine levels negatively correlated with $I F N G$ methylation levels. This result suggests that $\mathrm{CpG} 2$ methylation in IFNG contributes to $\mathrm{EH}$ possibly by increasing creatinine levels. Further studies are needed to clarify the pathways involved.

The results of this study indicate that the hypomethylation of $\mathrm{CpG} 2$ in IFNG contributes to $\mathrm{EH}$. The $\mathrm{CpG} 2$ site may play an epigenetic role in the pathogenesis of $\mathrm{EH}$. Further research is needed to determine the influence of epigenetic markers and determinants of disease progression, as well as their potential diagnostic and theranostic utility. These data may improve the diagnosis and treatment of $\mathrm{EH}$.

\section{Acknowledgments}

This work was supported by the National Natural Science Foundation of China (Grant No. 81773528); Ningbo Scientific Innovation Team for Environmental Hazardous Factor Control and Prevention (Grant No. 2016C51001); Zhejiang Province Social Development Research Project (Grant No. 2016C33178); K.C. Wong Magna Fund in Ningbo University, Ningbo Social Development Research Project (Grant No. 2014C50051).

\section{Conflict of Interest}

The authors declare no conflict of interest. 


\section{References}

Aavik, E., Lumivuori, H., Leppanen, O., Wirth, T., Hakkinen, S.K., Brasen, J.H., Beschorner, U., Zeller, T., Braspenning, M., van Criekinge, W., Makinen, K. \& Yla-Herttuala, S. (2015) Global DNA methylation analysis of human atherosclerotic plaques reveals extensive genomic hypomethylation and reactivation at imprinted locus $14 \mathrm{q} 32$ involving induction of a miRNA cluster. Eur. Heart J., 36, 993-1000.

Amirzargar, A., Lessanpezeshki, M., Fathi, A., Amirzargar, M., Khosravi, F., Ansaripour, B. \& Nikbin, B. (2005) TH1/TH2 cytokine analysis in Iranian renal transplant recipients. Transplant. Proc., 37, 2985-2987.

Bassil, C.F., Huang, Z. \& Murphy, S.K. (2013) Bisulfite pyrosequencing. Methods Mol. Biol., 1049, 95-107.

Bay-Richter, C., Hallberg, L., Ventorp, F., Janelidze, S. \& Brundin, L. (2012) Aldosterone synergizes with peripheral inflammation to induce brain IL-1 $\beta$ expression and depressive-like effects. Cytokine, 60, 749-754.

Bergman, Y. \& Cedar, H. (2013) DNA methylation dynamics in health and disease. Nat. Struct. Mol. Biol., 20, 274-281.

Bynoté, K.K., Hackenberg, J.M., Korach, K.S., Lubahn, D.B., Lane, P.H. \& Gould, K.A. (2008) Estrogen receptor-alpha deficiency attenuates autoimmune disease in $(\mathrm{NZB} \times \mathrm{NZW}) \mathrm{F} 1$ mice. Genes Immun., 9, 137-152.

Carr, E.L., Kelman, A., Wu, G.S., Gopaul, R., Senkevitch, E., Aghvanyan, A., Turay, A.M. \& Frauwirth, K.A. (2010) Glutamine uptake and metabolism are coordinately regulated by ERK/MAPK during T lymphocyte activation. J. Immunol., 185, 1037-1044.

Castro, R., Rivera, I., Struys, E.A., Jansen, E.E., Ravasco, P., Camilo, M.E., Blom, H.J., Jakobs, C. \& Tavares de Almeida, I. (2003) Increased homocysteine and S-adenosylhomocysteine concentrations and DNA hypomethylation in vascular disease. Clin. Chem., 49, 1292-1296.

Chang, C.H., Curtis, J.D., Maggi, L.B. Jr., Faubert, B., Villarino, A., O’Sullivan, D., Huang, S.C.C., Vanderwindt, G.W., Blagih, J., Qiu, J., Weber, J.D., Pearce, E.J., Jones, R.G. \& Pearce, E.L. (2013) Posttranscriptional control of T cell effector function by aerobic glycolysis. Cell, 153, 1239-1251.

Choubey, D., Panchanathan, R., Duan, X., Liu, H. \& Liu, H. (2011) Emerging roles for the interferon-inducible p200-family proteins in sex bias in systemic lupus erythematosus. J. Interferon Cytokine Res., 31, 893-906.

Deaton, A.M. \& Bird, A. (2011) CpG islands and the regulation of transcription. Genes Dev., 25, 1010-1022.

Denton, A.E., Russ, B.E., Doherty, P.C., Rao, S. \& Turner, S.J. (2011) Differentiation-dependent functional and epigenetic landscapes for cytokine genes in virus-specific CD8+ T cells. Proc. Natl. Acad. Sci. USA, 108, 15306-15311.

Dong, J., Chang, H.D., Ivascu, C., Qian, Y., Rezai, S., Okhrimenko, A., Cosmi, L., Maggi, L., Eckhardt, F., Wu, P., Sieper, J., Alexander, T., Annunziato, F., Gossen, M., Li, J., et al. (2013) Loss of methylation at the IFNG promoter and CNS-1 is associated with the development of functional IFN- $\gamma$-memory in human CD4(+) T lymphocytes. Eur. J. Immunol., 43, 793-804.

Fan, R., Mao, S., Zhong, F., Gong, M., Yin, F., Hao, L. \& Zhang, L. (2015a) Association of AGTR1 promoter methylation levels with essential hypertension risk: a matched case-control study. Cytogenet. Genome Res., 147, 95-102.

Fan, R., Wang, W.J., Zhong, Q.L., Duan, S.W., Xu, X.T., Hao, L.M., Zhao, J. \& Zhang, L.N. (2015b) Aberrant methylation of the GCK gene body is associated with the risk of essential hypertension. Mol. Med. Rep., 12, 2390-2394.

Feinberg, A.P. (2008) Epigenetics at the epicenter of modern medicine. JAMA, 299, 1345-1350.

Gabb, G.M., Mangoni, A.A., Anderson, C.S., Cowley, D., Dowden,
J.S., Golledge, J., Hankey, G.J., Howes, F.S., Leckie, L., Perkovic, V., Schlaich, M., Zwar, N.A., Medley, T.L. \& Arnolda, L. (2016) Guideline for the diagnosis and management of hypertension in adults - 2016. Med. J. Aust., 205, 85-89.

Glier, M.B., Green, T.J. \& Devlin, A.M. (2014) Methyl nutrients, DNA methylation, and cardiovascular disease. Mol. Nutr. Food Res., 58, 172-182.

Gozalbo, D., Maneu, V. \& Gil, M.L. (2014) Role of IFN-gamma in immune responses to Candida albicans infections. Front. Biosci. (Landmark Ed), 19, 1279-1290.

Gu, T., Mao, S., Fan, R., Zhong, F., Zhu, F., Hao, L., Zhang, L. \& Yin, F. (2016) Interactions between CYP11B2 promoter methylation and smoking increase risk of essential hypertension. Biomed. Res. Int., 2016,1454186.

Guida, F., Sandanger, T.M., Campanella, G., Polidoro, S., Palli, D., Krogh, V., Tumino, R., Sacerdote, C., Panico, S., Severi, G., Kyrtopoulos, S.A., Georgiadis, P., Vermoulen, R.C., Lund, E., Vineis, P. \& Chadeau-Hyam, M. (2015) Dynamics of smoking-induced genome-wide methylation changes with time since smoking cessation. Hum. Mol. Genet., 24, 23492359.

Hamlyn, J.M. \& Manunta, P. (2011) Endogenous ouabain: a link between sodium intake and hypertension. Curr. Hypertens. Rep., 13, 14-20.

Hering, D., Kucharska, W., Kara, T., Somers, V.K., Parati, G. \& Narkiewicz, K. (2013) Effects of acute and long-term slow breathing exercise on muscle sympathetic nerve activity in untreated male patients with hypertension. J. Hypertens., 31, 739-746.

Ishida, K., Kobayashi, T., Ito, S., Komatsu, Y., Yokoyama, T., Okada, M., Abe, A., Murasawa, A. \& Yoshie, H. (2012) Interleukin-6 gene promoter methylation in rheumatoid arthritis and chronic periodontitis. J. Periodontol., 83, 917-925.

Jacobs, S.R., Herman, C.E., Maciver, N.J., Wofford, J.A., Wieman, H.L., Hammen, J.J. \& Rathmell, J.C. (2008) Glucose uptake is limiting in T cell activation and requires CD28-mediated Akt-dependent and independent pathways. J. Immunol., 180, 4476-4486.

Jiang, D., Zheng, D., Wang, L., Huang, Y., Liu, H., Xu, L., Liao, Q., Liu, P., Shi, X., Wang, Z., Sun, L., Zhou, Q., Li, N., Xu, L., Ye, M., et al. (2013) Elevated PLA2G7 gene promoter methylation as a gender-specific marker of aging increases the risk of coronary heart disease in females. PLoS One, 8, e59752.

Jjingo, D., Conley, A.B., Yi, S.V., Lunyak, V.V. \& Jordan, I.K. (2012) On the presence and role of human gene-body DNA methylation. Oncotarget, 3, 462-474.

Kawano, H., Saeki, H., Kitao, H., Tsuda, Y., Otsu, H., Ando, K., Ito, S., Egashira, A., Oki, E., Morita, M., Oda, Y. \& Maehara, Y. (2014) Chromosomal instability associated with global DNA hypomethylation is associated with the initiation and progression of esophageal squamous cell carcinoma. Ann. Surg. Oncol., 21 Suppl 4, S696-702.

Klinker, M.W., Marklein, R.A., Lo Surdo, J.L., Wei, C.H. \& Bauer, S.R. (2017) Morphological features of IFN- $\gamma$-stimulated mesenchymal stromal cells predict overall immunosuppressive capacity. Proc. Natl. Acad. Sci. USA, 114, E2598-E2607.

Lópezjaramillo, P., Herrera, E., Garcia, R.G., Camacho, P.A. \& Castillo, V.R. (2008) Inter-relationships between body mass index, C-reactive protein and blood pressure in a Hispanic pediatric population. Am. J. Hypertens., 21, 527-532.

Lin, C.F., Lin, C.M., Lee, K.Y., Wu, S.Y., Feng, P.H., Chen, K.Y., Chuang, H.C., Chen, C.L., Wang, Y.C., Tseng, P.C. \& Tsai, T.T. (2017) Escape from IFN- $\gamma$-dependent immunosurveillance in tumorigenesis. J. Biomed. Sci., 24, 10.

Lubina-Dąbrowska, N., Stepień, A., Sulkowski, G., DąbrowskaBouta, B., Langfort, J. \& Chalimoniuk, M. (2017) Effects of IFN- $\beta 1 \mathrm{a}$ and IFN- $\beta 1 \mathrm{~b}$ treatment on the expression of cytokines, inducible NOS (NOS type II), and myelin proteins in 
animal model of multiple sclerosis. Arch. Immunol. Ther. Exp. (Warsz.), 65, 325-338.

Macintyre, A.N., Gerriets, V.A., Nichols, A.G., Michalek, R.D., Rudolph, M.C., Deoliveira, D., Anderson, S.M., Abel, E.D., Chen, B.J., Hale, L.P. \& Rathmell, J.C.(2014) The glucose transporter glut1 is selectively essential for CD4 T cell activation and effector function. Cell Metab., 20, 61-72.

Mao, S., Gu, T., Zhong, F., Fan, R., Zhu, F., Ren, P., Yin, F. \& Zhang, L. (2017a) Hypomethylation of the Toll-like receptor-2 gene increases the risk of essential hypertension. Mol. Med. Rep., 16, 964-970.

Mao, S.Q., Sun, J.H., Gu, T.L., Zhu, F.B., Yin, F.Y. \& Zhang, L.N. (2017b) Hypomethylation of interleukin-6 (IL-6) gene increases the risk of essential hypertension: a matched casecontrol study. J. Hum. Hypertens., 31, 530-536.

Mitu, F., Stefanachi, E. \& Leon, M.M. (2013) The incidence of essential hypertension in elderly patients with metabolic syndrome. Rev. Med. Chir. Soc. Med. Nat. Iasi., 117, 630-634.

Mohammadnia, M., Solgi, G., Ranjbar, M., Shahrestani, T., Edalat, R., Razavi, A., Nikbin, B., Pourmand, G., Amirzargar, M., Sarafnejad, A. \& Amirzargar, A.A. (2011) Serum levels of interleukin (IL)-10, IL-17, transforming growth factor (TGF)$\beta 1$, and interferon- $\gamma$ cytokines and expression levels of IL-10 and TGF- $\beta 1$ genes in renal allograft recipients after donor bone marrow cell infusion. Transplant. Proc., 43, 495-499.

Perloff, D., Grim, C., Flack, J., Frohlich, E.D., Hill, M., Mcdonald, M. \& Morgenstern, B.Z. (1993) Human blood pressure determination by sphygmomanometry. Circulation, 88, 2460-2470.

Post, W.S., Goldschmidt-Clermont, P.J., Wilhide, C.C., Heldman, A.W., Sussman, M.S., Ouyang, P., Milliken, E.E. \& Issa, J.P. (1999) Methylation of the estrogen receptor gene is associated with aging and atherosclerosis in the cardiovascular system. Cardiovasc. Res., 43, 985-991.

Reynolds, L.M., Wan, M., Ding, J., Taylor, J.R., Lohman, K., Su, D., Bennett, B.D., Porter, D.K., Gimple, R., Pittman, G.S., Wang, X., Howard, T.D., Siscovick, D., Psaty, B.M., Shea, S., et al. (2015) DNA methylation of the aryl hydrocarbon receptor repressor associations with cigarette smoking and subclinical atherosclerosis. Circ. Cardiovasc. Genet., 8, 707-716.

Rivera, C., Gurard-Levin, Z.A., Almouzni, G. \& Loyola, A. (2014) Histone lysine methylation and chromatin replication. Biochim. Biophys. Acta, 1839, 1433-1439.

Sullivan, K.E., Reddy, A.B., Dietzmann, K., Suriano, A.R., Kocieda, V.P., Stewart, M. \& Bhatia, M. (2007) Epigenetic regulation of tumor necrosis factor alpha. Mol. Cell. Biol., 27, 5147-5160.

Suzuki, M.M. \& Bird, A. (2008) DNA methylation landscapes: provocative insights from epigenomics. Nat. Rev. Genet., 9, 465-476.
Taddei, S., Caraccio, N., Virdis, A., Dardano, A., Versari, D., Ghiadoni, L., Ferrannini, E., Salvetti, A. \& Monzani, F. (2006) Low-grade systemic inflammation causes endothelial dysfunction in patients with Hashimoto's thyroiditis. J. Clin. Endocrinol. Metab., 91, 5076-5082.

Teschendorff, A.E., Yang, Z., Wong, A., Pipinikas, C.P., Jiao, Y., Jones, A., Anjum, S., Hardy, R., Salvesen, H.B. \& Thirlwell, C. (2015) Correlation of smoking-associated DNA methylation changes in buccal cells with DNA methylation changes in epithelial cancer. JAMA Oncol., 1, 476-485.

Tirado-Magallanes, R., Rebbani, K., Lim, R., Pradhan, S. \& Benoukraf, T. (2017) Whole genome DNA methylation: beyond genes silencing. Oncotarget, 8, 5629-5637.

Ulrich, C.M., Toriola, A.T., Koepl, L.M., Sandifer, T., Poole, E.M., Duggan, C., Mctiernan, A. \& Issa, J.P. (2012) Metabolic, hormonal and immunological associations with global DNA methylation among postmenopausal women. Epigenetics, 7, 1020-1028.

Wang, J.G., Staessen, J.A., Fagard, R.H., Birkenhager, W.H., Gong, L. \& Liu, L. (2001) Prognostic significance of serum creatinine and uric acid in older Chinese patients with isolated systolic hypertension. Hypertension, 37, 1069-1074.

Wise, I.A. \& Charchar, F.J. (2016) Epigenetic modifications in essential hypertension. Int. J. Mol. Sci., 17, 451.

Yan, Q., Sun, D., Li, X., Chen, G., Zheng, Q., Li, L., Gu, C. \& Feng, B. (2016) Association of blood glucose level and hypertension in elderly Chinese subjects: a community based study. BMC Endocr. Disord., 16, 40.

Yazici, M.U., Orhan, D., Kale, G., Besbas, N. \& Ozen, S. (2014) Studying IFN-gamma, IL-17 and FOXP3 in pediatric lupus nephritis. Pediatr. Nephrol., 29, 853-862.

Zacharia, L.C., Dubey, R.K., Mi, Z. \& Jackson, E.K. (2003) Methylation of 2-hydroxyestradiol in isolated organs. Hypertension, 42, 82-87.

Zhang, Y., Florath, I., Saum, K.U. \& Brenner, H. (2016) Selfreported smoking, serum cotinine, and blood DNA methylation. Environ. Res., 146, 395-430.

Zhang, Y., Yang, R., Burwinkel, B., Breitling, L.P. \& Brenner, H. (2014) F2RL3 methylation as a biomarker of current and lifetime smoking exposures. Environ. Health Perspect., 122, $131-137$

Zhou, J., Xiao, X.M. \& Wu, Y.H. (2014) Expression of interferon- $\gamma$ in decidual natural killer cells from women with hypertensive disorder complicating pregnancy. J. Obstet. Gynaecol. Res., 40, 670-676.

Zhou, P., Cowled, C., Marsh, G.A., Shi, Z., Wang, L.F. \& Baker, M.L. (2011) Type III IFN receptor expression and functional characterisation in the pteropid bat, Pteropus alecto. PLoS One, 6, e25385. 